\title{
Epidemiology and Antifungal Susceptibility of Candida Species Isolated from Urinary Tract Infections: A Study from an Intensive Care Unit of a Tertiary Care Hospital
}

Sir,

Nowadays, we see a change in the epidemiology and antifungal susceptibility of various Candida spp. isolated from urine samples. In many centers, worldwide, non-albicans Candida spp. which appear to be better adapted to the urinary tract environment have now replaced Candida albicans as the predominant pathogen in nosocomial urinary tract infections (UTIs). ${ }^{[1]}$ In addition, because of increased resistance to antifungal agents and changing epidemiology of the Candida species implicated in UTIs, there is importance of speciation of Candida strains before initiating the antifungal treatment. ${ }^{[2]}$

In this prospective study, conducted in the multidisciplinary Intensive Care Unit (ICU) of our hospital, the urine samples from critically ill patients were collected using proper aseptic technique in leak-proof sterile containers. The patients with urinary catheter for at least $72 \mathrm{~h}$ with previous urine culture sterile for Candida spp. were included in the study. To rule out the colonization from true infection, the following observations were considered significant, consistent with true candiduria:

- A pure colony of Candida spp. on culture with a colony count of $\geq 10^{4} \mathrm{CFU} / \mathrm{ml}$

- Presence of pus cells on wet mount examination

- Growth of Candida spp. on repeat urine culture after catheter removal. $^{[3]}$

The Candida isolates were speciated by germ tube test, carbohydrate assimilation, and fermentation tests, testing on corn meal agar and CHROM Agar Candida (HiMedia-HiCrome ${ }^{\mathrm{TM}}$ Candida Differential Agar). ${ }^{[3]}$ The antifungal susceptibility testing of the Candida isolates was performed to fluconazole, itraconazole, flucytosine, and amphotericin B by the microbroth dilution method. ${ }^{[4]}$

A total of 664 urine samples were received from 340 patients admitted in ICU during the study period and were processed following standard microbiological procedures. Out of all the samples, the growth of pure Candida spp. was observed in 75 urine cultures obtained from 60 patients (17.64\%). In 15 patients, the same strain of Candida species was isolated on repeat urine culture. The most common species isolated was C. albicans $58.7 \%$ (44) followed by Candida tropicalis 24\% (18) and Candida parapsilosis 17.3\% (13). Drug resistance to fluconazole was observed in $62.7 \%$ strains of Candida spp., among which non-albicans Candida spp. showed more than $80 \%$ fluconazole resistance while $45 \%$ drug resistance was observed in C. albicans. Resistance to flucytosine and amphotericin B was seen in $6.67 \%$ and $2.67 \%$ strains, respectively, of all Candida spp.

A study from Mangalore, India, reported a rate of $2.27 \%$ candiduria in both out- and inpatients, while another Indian study done in critically ill patients found the rate to be as high as $21.96 \%{ }^{[2]}$

The role of species other than C. albicans as emergent pathogens of UTI has been well emphasized. Mishra et al. in their respective studies reported C. albicans as the most common Candida spp. implicated in UTIs followed by non-albicans Candida spp., the finding similar to our study. ${ }^{[2]}$ Similar resistance has been seen in a study by Mishra et al. and Yashavanth et al., respectively. ${ }^{[2,5]}$

In conclusion, it is important to differentiate colonization from true infection by clinical signs and microscopic evidence of inflammation. Due to the risk of invasive candidiasis, aggressive management is needed to prevent mortality in these cases. Antifungal resistance in Candida is adding another challenge for the intensivist.

\section{Financial support and sponsorship}

Nil.

\section{Conflicts of interest}

There are no conflicts of interest.

Priya Datta, Mandeep Kaur, Satinder Gombar', Jagdish Chander Departments of Microbiology and ${ }^{1}$ Anaesthesia and Intensive Care, Government Medical College Hospital, Chandigarh, India

\section{Address for correspondence: Dr. Priya Datta, Department of Microbiology, Government Medical College Hospital, Sector 32, Chandigarh - 160 030, India. E-mail: drpriyadatta@hotmail.com}

\section{RefERENCES}

1. Sobel JD, Fisher JF, Kauffman CA, Newman CA. Candida urinary tract infections - Epidemiology. Clin Infect Dis 2011;52 Suppl 6:S433-6.

2. Mishra M, Agrawal S, Raut S, Kurhade AM, Powar RM. Profile of yeasts isolated from urinary tracts of catheterized patients. J Clin Diagn Res 2014;8:44-6.

3. Chander J. Textbook of Medical Mycology. $3^{\text {rd }}$ ed. New Delhi: Mehta Publishers; 2009.

4. CLSI. Reference Method for Broth Dilution Antifungal Susceptibility Testing of Yeasts; Third Informational Supplement. CLSI Document M27-S3. Wayne, PA: Clinical and Laboratory Standards Institute; 2008. 
5. Yashavanth R, Shiju MP, Bhaskar UA, Ronald R, Anita KB. Candiduria: Prevalence and trends in antifungal susceptibility in a tertiary care hospital of Mangalore. J Clin Diagn Res 2013;7:2459-61.

This is an open access article distributed under the terms of the Creative Commons Attribution-NonCommercial-ShareAlike 3.0 License, which allows others to remix, tweak, and build upon the work non-commercially, as long as the author is credited and the new creations are licensed under the identical terms.

\begin{tabular}{|l|l|}
\hline \multicolumn{2}{|c|}{ Access this article online } \\
\hline Quick Response Code: & Website: \\
\hline & www.ijccm.org \\
\hline & \\
\hline
\end{tabular}

How to cite this article: Datta P, Kaur M, Gombar S, Chander J. Epidemiology and antifungal susceptibility of Candida species isolated from urinary tract infections: A study from an intensive care unit of a tertiary care hospital. Indian J Crit Care Med 2018;22:56-7.

C 2018 Indian Journal of Critical Care Medicine | Published by Wolters Kluwer - Medknow 